\title{
Role for Aldosterone in Blood Pressure Regulation of Obese Adolescents
}

\author{
ALBERT P. ROCCHINI, MD, VICTOR L. KATCH, EdD, ROGER GREKIN, MD, \\ CATHERINE MOOREHEAD, BS, and JUDITH ANDERSON, PhD
}

To determine the role of aldosterone in the regulation of blood pressure (BP) in obese adolescents, supine and 2-hour upright plasma renin activity (PRA), and aldosterone and cortisol were measured in 10 nonobese and $\mathbf{3 0}$ obese adolescents before and after a 20-week weight loss program. The obese adolescents had significantly higher supine and 2-hour upright plasma aldosterone concentrations ( $17 \pm 8$ vs $6 \pm 2 \mathrm{ng} / \mathrm{dl}[\mathrm{p}<0.01$ supine obese vs nonobese] and $30 \pm 11$ vs $14 \pm 8 \mathrm{ng} / \mathrm{dl}$ [p $<0.012$-hour upright]). Although PRA was not significantly different between the 2 groups of children, a given increment in PRA produced a greater increment in aldosterone in the obese adolescents. In addition, obese subjects had a significantly increased mean BP (93 \pm 12 vs $74 \pm 8, p<0.005)$ and a weak correlation between BP and plasma aldosterone concentration. Compared with an obese control group, weight loss resulted in a significant decrease in plasma aldosterone $(p<0.01)$ without an associated decrease in PRA. After weight loss there was also a significant decrease in the slope of the posture-induced relation between PRA and aldosterone. In addition to weight loss being associated with a significant decrease in BP $(p<0.01)$, there was a significant correlation between the change in plasma aidosterone and the change in mean BP ( $r$ $=0.538 ; p<0.002$ change in upright aldosterone vs change in mean BP). Obese adolescents have an increased plasma aldosterone concentration that may be important in the regulation of their BP.

(Am J Cardiol 1986;57:613-618)
S it has been known that body weight and arterial pressure are related. However, little is known about the mechanism of this relation. ${ }^{1}$ One physiologic change that may be partially responsible for hypertension in the obese person is excess mineral corticoid activity. Scavo et $\mathrm{al}^{2,3}$ reported that although obese adults have normal plasma renin activity (PRA), they have an increased plasma aldosterone concentration and an increased aldosterone secretion rate. In obese adults with essential hypertension, Hiramatsu et $\mathrm{al}^{4}$ documented that with increasing body weight PRA

From the Section of Pediatric Cardiology, C.S. Mott Children's Hospital, and the Departments of Pediatrics and Internal Medicine, University of Michigan Medical Center, Ann Arbor, Michigan. This study was supported by Grants 1RO1 AM-309-89 and MO 1RR00042-21 from the National Institutes of Health, and Grant HL 18575 from the National Heart, Lung, and Blood Institute, National Institutes of Health, Bethesda, Maryland. Manuscript received May 9, 1985; revised manuscript reccived August 7, 1985, accepted August 12, 1985.

Address for reprints: Albert P. Rocchini, C.S. Mott Children's Hospital, University of Michigan Medical School, Box 66 , Ann Arbor, Michigan 48109. decreases and plasma aldosterone concentration remains unchanged. Tuck et $a l^{5}$ demonstrated that with weight loss both PRA and plasma aldosterone concen. tration decrease. Although these and other observations ${ }^{6,7}$ suggest that in obese subjects abnormalities in the renin-aldosterone axis are present, the effect of these abnormalities on blood pressure (BP) is unclear. Therefore, we evaluated the role of aldosterone in the regulation of $\mathrm{BP}$ in 30 obese adolescents before and after a 20 -week weight loss program.

\section{Methods}

Thirty obese adolescents, mean age 12.7 years (range 10 to 15), and 10 nonobese adolescents, mean age 12.2 years (range 10 to 14). were studied. Obesity was defined as weight for height above the 75th percentile for age and sex and triceps and subscapular skin folds above the 80th percentile for age and sex. The obese subjects were randomly placed into 1 of 3 groups. Group I consisted of 10 obese adolescents placed in a weight loss program composed of diet and behavior change. The diet was a modification of the caloric exchange program and was designed to produce approximately 1 pound per week of weight loss 
TABLE I Pertinent Clinical, Hemodynamic and Electrolyte Data in 30 Obese and to Nonobese Adolescents

\begin{tabular}{lccc}
\hline & $\begin{array}{c}\text { Obese } \\
(n=30)\end{array}$ & $\begin{array}{c}\text { Nonobese } \\
(n=10)\end{array}$ & p Value \\
\hline Age $(\mathrm{gr})$ & $12.7 \pm 2.2$ & $12.2 \pm 3.0$ & NS \\
Weight $(\mathrm{kg})$ & $75.8 \pm 22$ & $42.2 \pm 13$ & $\mathrm{p}<0.001$ \\
$\%$ fat & $40 \pm 6$ & $20 \pm 7$ & $\mathrm{p}<0.001$ \\
Mean BP $(\mathrm{mm} \mathrm{Hg})$ & $93 \pm 12$ & $74 \pm 8$ & $\mathrm{p}<0.005$ \\
HR (beats/min) & $86 \pm 12$ & $77 \pm 6$ & $\mathrm{p}<0.05$ \\
$\mathrm{~K}^{+}(\mathrm{mEq} / \mathrm{liter})$ & $4.0 \pm 0.2$ & $4.3 \pm 0.2$ & $\mathrm{p}<0.03$ \\
$\mathrm{NA}$ (mEq/liter) & $142 \pm 2$ & $138 \pm 3$ & $\mathrm{p}<0.03$ \\
UNa (mEq/24 hr) & $212 \pm 77$ & $136 \pm 14$ & $\mathrm{p}<0.02$ \\
\hline
\end{tabular}

$\mathrm{BP}=$ blood pressure; $\mathrm{HR}=$ heart rate; $\mathrm{NS}=$ not significant; $\mathrm{UNa}=$ urinary sodium excretion.

(1,200 to 1,800 calories/day). The behavior change component consisted of a 1-hour class each week for 20 weeks that centered around record keeping, stimulus control, changing eating typography, and reinforcement of altered behavior. Group II consisted of 10 obese adolescents placed in a weight loss program consisting of diet, behavior change and exercise. The diet and behavior change were the same as in group I. The exercise program consisted of three 1-hour classes per week for 20 weeks, centering around activities designed to maintain heart rate for at least 40 minutes at more than $50 \%$ of maximal exercise rate. Group III consisted of 10 obese adolescents placed in a control group who received no weight loss program for 20 weeks. All 30 obese subjects were tested before and after the 20 weeks. The 10 nonobese adolescents were tested only once.

Experimental protocol: All patients were admitted overnight to the Clinical Research Center. BP was measured every 5 minutes for 30 minutes in a quiet room using a Critikon pressure monitor (model 1165) and an appropriate-size cuff. Mean BP was calculated as diastolic pressure plus one-third pulse pressure. All patients fasted after $10 \mathrm{PM}$ of the evening preceding the study and were maintained in a supine position after 4 AM on the morning of the study. A heparin lock was placed at 7:30 AM, and with the patient in the supine position, blood was obtained for PRA, plasma aldosterone, plasma cortisol, serum sodium and potassium. After being upright and ambulating for 2 hours, repeat blood samples were obtained. Dietary sodium intake was assessed in all patients by measuring the 24-hour urinary sodium excretion the day before the study.

Laboratory procedures: Weight was measured using a beam balance scale and height was measured to the nearest $0.1 \mathrm{~cm}$ using a stabilometer. Body composition (percent fat and lean body weight) was measured by hydrostatic weighing. ${ }^{8}$ Sodium concentration was determined by flame photometry. Aldosterone, cortisol and PRA were measured by radioimmunoassay. ${ }^{9-11}$

Statistical analysis: Statistical analysis was performed using analysis of variance to compare differences between the nonobese and obese adolescents. To compare differences between the 3 obese groups before and after 20 weeks of weight loss, we used a $2 \times$

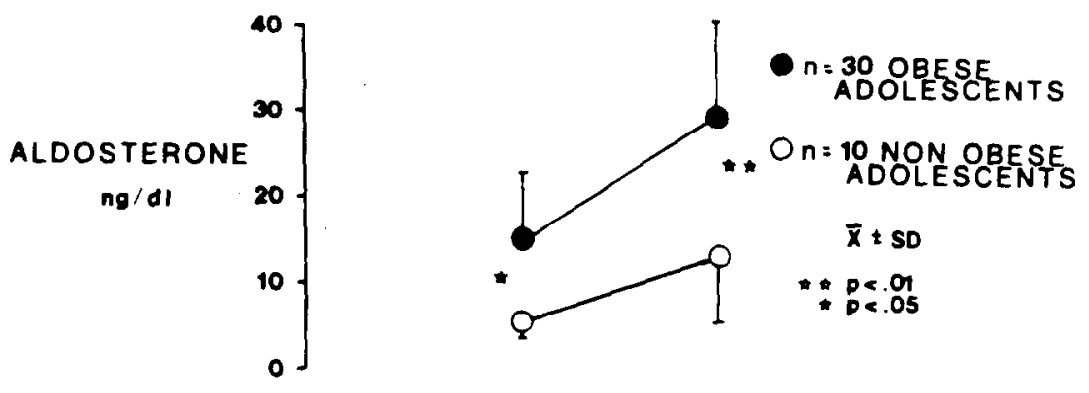

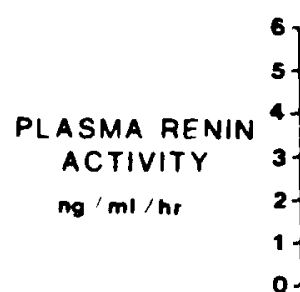
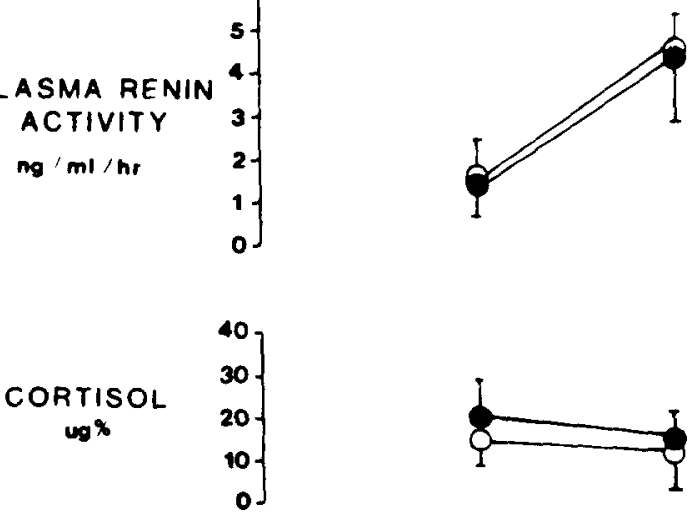

FIGURE 1. Supine and 2-hour upright plasma aldosterone concentration, plasma renin activity and plasma cortisol concentration in $\mathbf{3 0}$ obese and $\mathbf{1 0}$ nonobese adolescents. SD = standard deviation. 
TABLE II Change in Body Composition, Blood Pressure, Aldosterone, Plasma Renin Activity and Electroiyles After sither a 20-Week Weight Loss Program or Control Period

\begin{tabular}{|c|c|c|c|c|c|c|}
\hline & \multicolumn{2}{|c|}{$\begin{array}{l}\text { Obese Control } \\
\qquad(n=10)\end{array}$} & \multicolumn{2}{|c|}{$\begin{array}{l}\text { Obese Diet } \\
(n=10)\end{array}$} & \multicolumn{2}{|c|}{$\begin{array}{l}\text { Obese Diet }+ \text { Exercise } \\
\qquad(n=10)\end{array}$} \\
\hline & Pre & Post & Pre & Post & Pre & Post \\
\hline Weight (kg) & $67.6 \pm 30$ & $71.9 \pm 25$ & $72.4 \pm 20$ & $69.9 \pm 17^{\ddagger}$ & $71 \pm 8$ & $69 \pm 9^{\dagger}$ \\
\hline$\%$ fat & $39 \pm 6$ & $41 \pm 9$ & $41 \pm 7$ & $36 \pm 7 \dagger \ddagger$ & $40 \pm 6$ & $34 \pm 5^{\dagger \ddagger}$ \\
\hline Height $(\mathrm{cm})$ & $157 \pm 9$ & $161 \pm 10^{\dagger}$ & $157 \pm 10$ & $161 \pm 9^{\dagger}$ & $157 \pm 6$ & $162 \pm 6^{\dagger}$ \\
\hline $\mathrm{BP}(\mathrm{mm} \mathrm{Hg})$ & $88 \pm 10$ & $93 \pm 13$ & $92 \pm 12$ & $81 \pm 7^{\dagger \ddagger}$ & $90 \pm 8$ & $82 \pm 4^{\dagger \ddagger}$ \\
\hline \multicolumn{7}{|l|}{ Aldo (ng/dl) } \\
\hline supine & $21 \pm 15$ & $18 \pm 6$ & $15 \pm 8$ & $10 \pm 6^{\dagger \ddagger}$ & $17 \pm 8$ & $9 \pm 4^{\dagger \ddagger}$ \\
\hline 2-hr upright & $29 \pm 8$ & $31 \pm 7$ & $28 \pm 8$ & $19 \pm 6^{t t}$ & $38 \pm 12$ & $19 \pm 4^{\dagger t}$ \\
\hline \multicolumn{7}{|l|}{ PRA (ngAl/ml/hr) } \\
\hline Supine & $1.9 \pm 1.2$ & $1.7 \pm 1.1$ & $1.4 \pm 0.8$ & $1.6 \pm 0.9$ & $1.6 \pm 0.95$ & $2.4 \pm 0.9$ \\
\hline 2-hr upright & $4.9 \pm 1.7$ & $3.8 \pm 1.3$ & $3.8 \pm 1.8$ & $4.9 \pm 1.5$ & $5.1 \pm 2.1$ & $4.9 \pm 1.6$ \\
\hline \multicolumn{7}{|l|}{ Cortisol $(\mu \mathrm{g} / \mathrm{d} l)$} \\
\hline Supine & $19 \pm 4$ & $19 \pm 4$ & $19 \pm 5$ & $15 \pm 3^{* \S}$ & $18 \pm 4$ & $15 \pm 2^{*}$ \\
\hline Serum $\mathrm{K}^{+}$(mEq/liter) & $4.0 \pm 0.2$ & $3.9 \pm 0.2$ & $3.9 \pm 0.25$ & $4.2 \pm 0.2^{* \xi}$ & $3.9 \pm 0.2$ & $4.2 \pm 0.3^{*} \xi$ \\
\hline $\mathrm{UNa}^{+}(\mathrm{mEq} / 24 \mathrm{hr})$ & $211 \pm 74$ & $194 \pm 62$ & $212 \pm 57$ & $184 \pm 33$ & $208 \pm 78$ & $195 \pm 77$ \\
\hline 24-hr urine creat. (g/day) & $1.1 \pm 0.4$ & $1.2 \pm 0.3$ & $1.2 \pm 0.3$ & $1.2 \pm 0.3$ & $1.2 \pm 0.2$ & $1.2+0.3$ \\
\hline
\end{tabular}

Pre vs post: ${ }^{*} p<0.05 ;{ }^{\dagger} p<0.01$; obese control vs obese diet or diet + exercise; ${ }^{\ddagger} p<0.01 ;{ }^{\S} p<0.05$.

Aldo = aldosterone; $\mathrm{BP}=$ mean blood pressure; Creat. = creatinine; $\mathrm{UNa}=$ urinary sodium excretion; $\mathrm{K}^{+}=$potassium; $\mathrm{Na}^{+}=$sodium; pre = before weight loss; post $=$ after 20 -week weight loss program or control period; PRA = plasma renin activity.

3 analysis of variance and the Scheffe $\mathrm{e}^{12}$ procedure for multiple comparisons.

Systolic and diastolic BPs were adjusted for age and sex by use of the standard deviation score $(z)$ calculated according to the formula $\mathrm{z}=\mathrm{x}-\mathrm{x} / \mathrm{SDx}$, where $\mathrm{x}=$ measured $B P, x=$ mean of the expected $B P$ for age and sex (Hanes II data $\left.{ }^{13}\right)$, and SDx $=$ standard deviation $\mathrm{x}$. Linear regression analysis was used to determine the correlation between posture-induced changes in PRA and plasma aldosterone in nonobese and obese adolescents before and after weight loss. Comparisons between regression slopes were made using analysis of variance. The homogeneity of variance was assessed by Bartlett's test. ${ }^{14}$ All results are expressed as mean \pm standard deviation.

\section{Results}

Compared with the 10 nonobese adolescents, the 30 obese adolescents had a higher mean BP ( $p<0.005)$ (Table I], They also had an increased 24-hour urinary sodium excretion rate $(p<0.02)$ and serum sodium concentration $(\mathrm{p}<0.03)$ and a decreased serum potassium concentration $(\mathrm{p}<0.03)$. The association of an elevated mean BP, a mildly decreased serum potassium concentration and a mildly increased serum sodium concentration in our obese adolescents is consistent with the possibility of an excess in mineral corticoid activity.

To evaluate the renin-angiotensin-aldosterone axis in adolescent obesity, we compared the changes in PRA and aldosterone concentration that occurred with acute postural change. Compared with nonobese adolescents, the obese adolescents had an elevated plasma aldosterone concentration in both the supine $(17 \pm$ 8 vs $6 \pm 2 \mathrm{ng} / \mathrm{dl}, \mathrm{p}<0.01)$ and upright $(30 \pm 11$ vs $14 \pm 8$ $\mathrm{ng} / \mathrm{dl}, \mathrm{p}<0.01$ ) positions (Fig. 1). However, despite the observed increase in plasma aldosterone, the 2 groups of children had similar changes in PRA.

Because BP in childhood is affected by both age and sex, in order to evaluate the relation between plasma aldosterone concentration and $\mathrm{BP}$, a $\mathrm{Z}$ score $\mathrm{BP}$ was determined for each adolescent. In the obese adolescents, there were correlations between both $\mathrm{Z}$ score systolic and diastolic BP and 2-hour upright plasma aldosterone concentration $(r=0.35$ and 0.56 , respectively, $p<0.05$ ), fat weight ( $r=0.35$ and 0.56 , respectively, $\mathrm{p}<0.05)$ and plasma potassium concentration $(\mathrm{r}$ $=0.42, p<0.05$ for diastolic BP]. The effect of weight loss on these variables was evaluated by comparing the changes in plasma aldosterone, PRA, plasma cortisol, serum sodium and potassium, body weight, fat weight and BP that occurred in 2 groups of obese adolescents after 20 weeks of weight loss vs that which occurred in a group of obese adolescents after a 20. week control period.

The two 20-week weight loss groups showed modest but significant decreases in body weight $(\mathrm{p}<0.01)$. In fact, all patients in the weight loss programs lost some weight, whereas all of the obese control patients gained weight. Since both the obese control group and weight loss groups had a significant $4-\mathrm{cm}$ increase in height ( $\mathrm{p}<0.01$ ), the modest decrease in body weight observed in the 2 weight loss groups was associated with marked changes in body composition (Table II). In addition, compared with the obese control subjects, the 2 weight loss groups had a significant decrease in fat weight $(p<0.01)$, mean BP ( $p<0.01)$, supine and upright plasma aldosterone $(p<0.01)$, plasma cortisol ( $p<0.03$ ) and serum sodium concentration ( $p<0.02$ ), and a small but significant increase in serum potassi- 
um concentration ( $\mathrm{p}<0.02$ ) (Table II). The decrease in mean $\mathrm{BP}$ during the 20 -week program significantly correlated with the change in plasma aldosterone $[\mathrm{r}=$ $0.38, p<0.03$ supine and $\mathrm{r}=0.54, \mathrm{p}<0.002$ upright) (Fig. 2), fat weight $(r=0.73, p<0.001)$, and body weight $(\mathrm{r}=0.60, \mathrm{p}<0.01)$. The changes in plasma aldosterone and changes in body weight and fat weight were significantly correlated $(\mathrm{r}=0.421, \mathrm{p}<0.05$ and $\mathrm{r}=0.61$, $\mathrm{p}$ $<0.01$, respectively]. There was also a significant correlation between change in mean BP and plasma aldo- sterone independent of the effect of body weight $(p=$ 0.05).

Although weight loss was associated with a significant decrease in plasma aldosterone concentration, we observed no significant change in PRA. However, weight loss markedly affected the relation between the posture-induced changes in PRA and plasma aldosterone. Before weight loss, the increment in plasma aldosterone between supine and upright posture divided by the increment in PRA was significantly in-
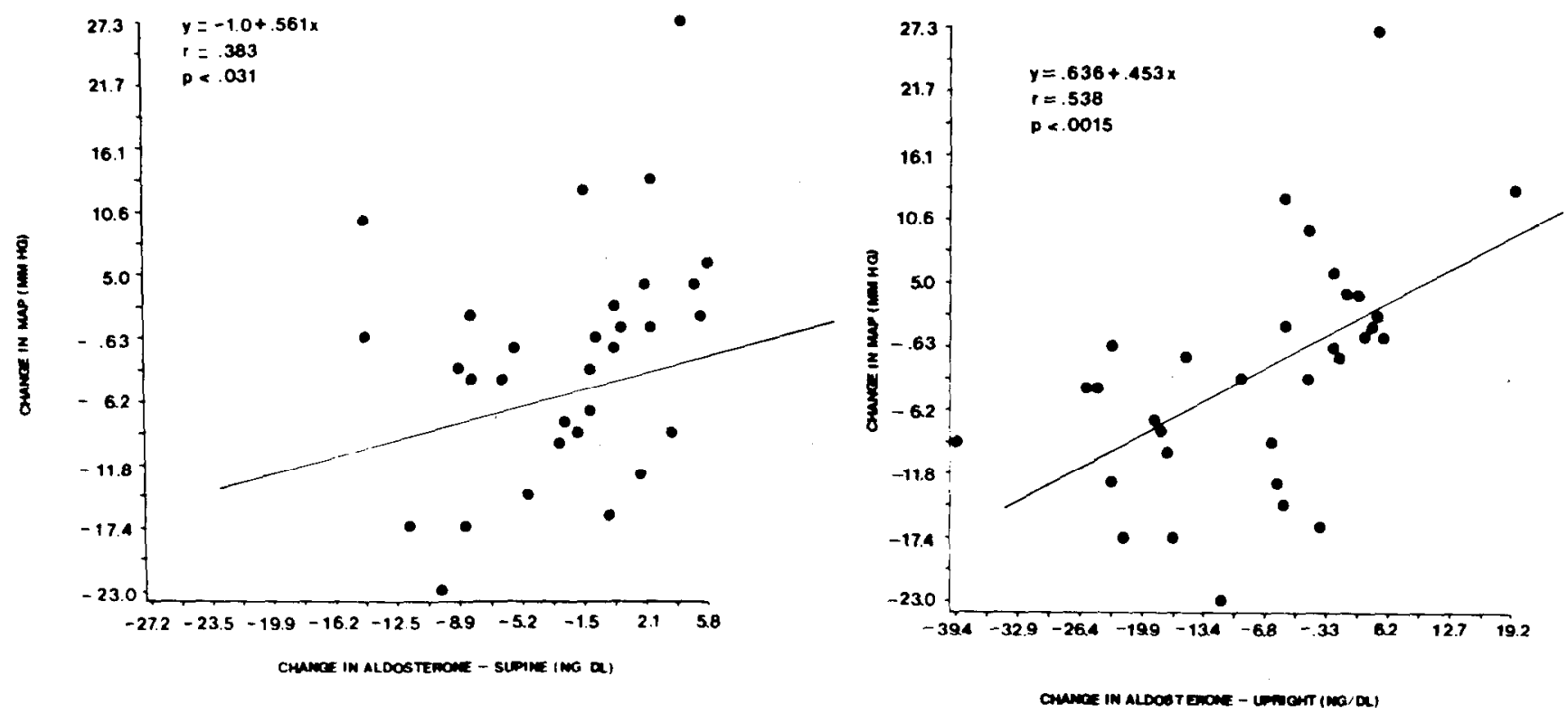

FIGURE 2. Regression relation between the change in mean arterial pressure (MAP) and the change in plasma aldosterone concentration during the 20-week study.

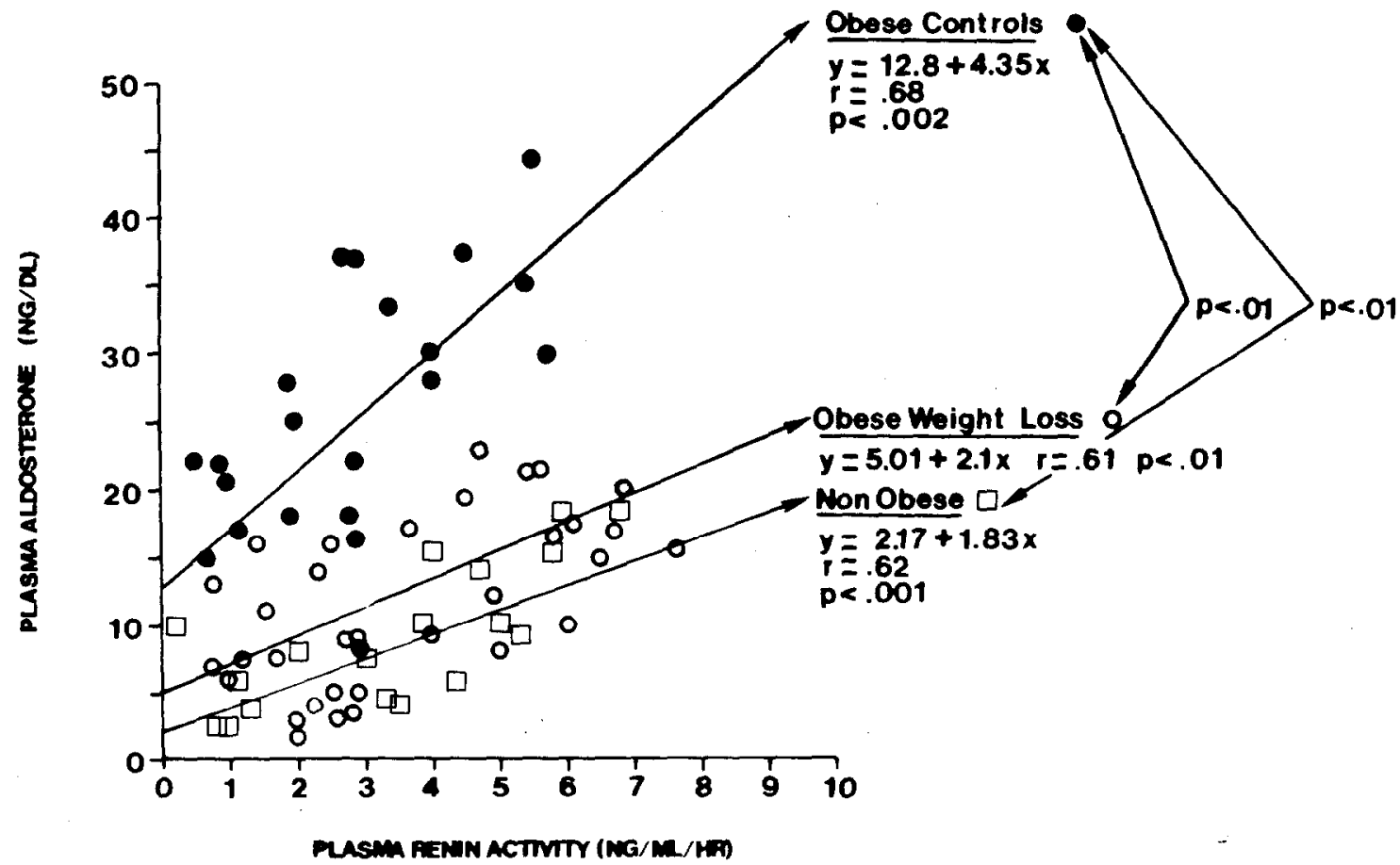

FIGURE 3. Regression relations between posture-induced changes in plasma renin activity and plasma aldosterone in 10 obese control subjects (dots), in 20 obese subjects after weight loss (circles) and in 10 nonobese subjects (squares). The 2 weight-loss groups were combined. 
creased in the obese adolescents $(1.8 \mathrm{vs} 4.4 \mathrm{ng} / \mathrm{dl}$ aldosterone $/ \mathrm{ng} / \mathrm{ml} /$ hour AI, $\mathrm{p}<0.01$ nonobese vs obese adolescents]. After the weight loss program, there was a significant decrease in the slope of the relation between PRA and aldosterone to the extent that only the obese control group still had a slope that was significantly greater than the nonobese adolescents (Fig. 3).

\section{Discussion}

In the present study, we have demonstrated that compared with nonobese adolescents, obese adolescents have a significantly higher plasma aldosterone concentration. Other investigators have also demonstrated abnormal aldosterone production in obesity. Garnett et a $l^{6}$ documented a mild increase in aldosterone secretion in 9 obese adults. In addition, Scavo et $\mathrm{al}^{2,3}$ demonstrated that in obese adults aldosterone secretion is significantly increased in both absolute values as well as when indexed to body surface area, the metabolic clearance rate of aldosterone is normal and the plasma aldosterone concentration is increased. However, unlike Scavo's study, in the present study, we also evaluated both the effect of weight loss on the hyperaldosteronism of obesity and the correlation between the increased plasma aldosterone concentration and BP. We observed that weight loss, either with or without exercise, produced a significant reduction in both plasma aldosterone concentration and $\mathrm{BP}$ and a small but significant increase in serum potassium concentration. In addition, the decrease in plasma aldosterone concentration significantly correlated with the observed decrease in mean BP. Thus, our data suggest, but do not prove, that the hyperaldosteronism associated with obesity may have contributed, in part, to the hypertension of obesity. Tuck et $\mathrm{al}^{5}$ demonstrated, as did we, that with weight loss, plasma aldosterone levels decrease while serum potassium concentration increases. However, unlike our study, Tuck did not demonstrate a statistically significant correlation between the decrease in aldosterone concentration and the decrease in mean BP. A possible explanation for the differences between the 2 studies may be that Tuck et al severely reduced caloric intake to $320 \mathrm{kcal} /$ day (almost starvation levels), whereas in the present study, only a mild reduction in caloric intake was used. Since Spark et $\mathrm{al}^{7}$ and Garnett et $\mathrm{al}^{6}$ demonstrated that with fasting wide swings in both aldosterone and PRA can occur, it is possible that these starvation-induced swings in aldosterone may have obscured the correlation between changes in plasma aldosterone and changes in mean BP.

The mechanism of hyperaldosteronism of obesity is unknown. Although aldosterone metabolism was not measured in this study, on the basis of the work of Scavo et $\mathrm{al}^{2,3}$ and Garnett et $\mathrm{al}^{6}{ }^{6}$ the hyperaldosteronism observed in our obese adolescents was probably a result of increased aldosterone secretion rather than decreased metabolic clearance. Aldosterone secretion is normally regulated by the renin-angiotensin system, serum potassium, ${ }^{15}$ sodium balance, ${ }^{16}$ ACTH activity ${ }^{17,18}$ and other less defined secretagogues. ${ }^{19}$ Our data suggest that the hyperaldosteronism of obesity may be the result of an abnormality either in the renin-angio- tensin system or in ACTH activity. With regard to the renin-angiotensin system, even though angiotensin II was not directly measured because PRA was normal and was not altered by weight loss, it is unlikely that an increase in plasma angiotensin II was present. However, based on the observation that a given increment in PRA produced a greater increment in aldosterone in the obese adolescents and that weight loss, in part, corrected this relation, adrenal sensitivity to angiotensin II may apparently be increased. ${ }^{20}$ Hiramatsu et $\mathrm{al}^{4}$ also observed that obese patients have an increased aldosterone/PRA ratio. Kisch et al ${ }^{21}$ and Marks et al, ${ }^{22}$ using a graded infusion of angiotensin II, demonstrated that some patients with ossential hypertension have increased adrenal sensitivity to angiotensin II. Many of Kisch's hypertensive patients may have been mildly obese. Since Shoback et $\mathrm{al}^{23}$ reported that a substantial subgroup of essential hypertensive patients have an abnormality in sodium-modulated renovascular and adrenal responsiveness to angiotensin II, our results suggest that a similar defect may also be present in obese adolescents. Further studies in obese adolescents before and after weight loss, using graded infusions of angiotensin II, are required to prove that obesity can produce a defect in tissue responsiveness to angiotensin II.

Finally, although we did not directly measure ACTH activity since weight loss was associated with a significant decrease in serum cortisol, it is possible that ACTH activity could have also decreased. Other investigators also demonstrated an increased cortisol excretion rate in obesity ${ }^{24,25}$; increased ACTH activity may also contribute to the hyperaldosteronism of obesity.

\section{References}

1. Dustan HP. Mechanisms of hypertension associated with obesity. Ann Intern Med 1983:98:860-864.

2. Scavo D, Borgia C, Iacobelli A. Aspetti di funzione corticosurrenalica nell'obesita'. Nota VI. Il comportamento della secrezione di aldosterone e della escrezione dei suoi metabolite nel corso di alcune prove dinamiche. Folia Endocrinol 1968;21:591-602

3. Scavo D, Iacobelli A, Borgia C. Aspetti di funzione corticosurrenalica nell'obesita'. Nota V. La secreziona giornalieia di aldosterone. Folia Endocrinol 1968;21:577-590.

4. Hiramatsu K, Yamada T, Ichikawak, Izumivama T, Nagata H. Changes in endocrine activity to obesity inpatients with essential hypertension. I Am Geriatr Soc 1981;29:25-30.

5. Tuck ML, Sowers J, Dornfeld L, Kledzik G, Maxwell M. The effect of weight reduction on blood pressure, plasma renin activity and plasma aldosterone levels in obese patients. N Engl I Med 1981;304:930-933

6. Garnett ES, Cohen C, Nahmias C, Viol G. The role of carbohydrate, renin and aldosterone in sudium retention during und ufter totul sturvation. Metabolism 1973:22:867-874.

7. Spark RF, Arky RA, Boulter PR, Saudek CD, Obrian JT. Renin, aldosterone and glucagon in the natruiresis of fasting. N Engl $Y$ Med 1975;292:13351340

8. Katch FI, Michael ED, Horvath SM. Estimation of body volume by underwater weighing description of a simple method. I Appl Physiol 1967; 23:811-813.

9. Antunes JR, Dale SL, Melby JC. Simplified radioimmunoassay for aldosterone using antiseria to aldosterone- $\gamma$-lactone. Steroids 1976;28:621-630.

10. Dash RJ, England BG, Midgley AR Jr, Niswender GD. A specific nonchro matographic radioimmunoassay for human plasma cortisol. Steroids 1975; 26:647-661.

11. Haber E, Koerner T, Page LB, Kliman B, Purnode A. Applicution of a radioimmunoassay for angiotensin $I$ to the physiologic measurements of plasma renin activity in normal human subjects. I Clin Endocrinol Metab $1969 ; 29: 1349-1355$.

12. Scheffe H. Analysis of Variance. New York: John Wiley \& Sons 1959:68-72

13. National Center for Health Statistics. Plan, operation, and results of a 
program of children's examinations. (Vital and health statistics. Series II: no.135, PHS no. 1000). Washington, DC: Public Health Services, U.S. Govt. Print. Off., November 1973:120-132.

14. Neter J, Wasserman W. Applied Linear Statistical Models; Regression, Analysis of Variance and Experimental Designs. Homewood, IL: Richard D. Irwin, 1974.

15. Dluhy RG, Axelrod L, Underwood RH, Williams GH. Studies of the control of plasma aldosterone concentration in man. Effect of dietary potassium and acute potassium infusions. I Clin Invest 1972;54:34-45.

16. Tuck ML, Dluhy RG, Williams GH. Sequential responses of the reninangiotensin-aldosterone axis to acute posterial change. Effect of dietary sodium. I Lab Clin Med 1975;86:754-763.

17. Tucci $\} R$, Espiner EA, Jagger PI. ACTH stimulation of aldosterone secretion in normal subjects and in patients with chronic adrenocortical insufficiency. I Clin Endocrinol Metab 1967;27:568-575.

18. Williams GH, Rose LI, Dluhy RG, Dingman JF, Lauler DP. Aldosterone response to sodium restriction and ACTH stimulation in panhypopituitarism. I Clin Endocrinol Metab 1971;32:27-35.

19. Gross MD, Grekin RJ, Gniadek TC, Villareal JZ. Suppression of aldoste- rone by cyprohepatadine in idiopathic aldosteronism. $N$ EngI / Med 1981; 305:181-185.

20. Moore TJ, Williams GH, Dluhy RG, Bavel SZ, Himathongkam T, Greenfield $M$. Altered renin-angiotensin-aldosterone relationship in normal renin essential hypertension. Circ Res 1977;41:167-171.

21. Kisch ES, Dluhy RG, Williams GH. Enhaneed aldosterone response to angiotensin II in human hypertension. Circ Res 1976:38:502-505.

22. Marks AD, Marks DB, Kanefsky TM, Adlin VE, Channick BJ. Enhanced adrenal responsiveness to angintensin II in patients with low renin hypertension. J Clin Endocrinol Metab 1979;48:266-270.

23. Shoback DM, Williams GH, Moore TI. Dluhy RG, Podolsky S. Hollenberg NK. Defect in the sodium-modulated tissue responsiveness to angiotensin $I I$ in essential hypertension. I Clin Invest 1983;72:2115-2124.

24. O'Connell M, Danforth E Jr, Horton ES, Salans L, Sims EAH. Experimental obesity in man. III. Adrenocortical function. I Clin Endocrinol Metab 1973:6:323-329.

25. Sims EAH, Danforth E Jr, Horton ES, Bray GA, Glennon JA, Salans LB. Endocrine and metabolic effects of experimental obesity in man. Recent Prog Hurn Res 1973;29:457-496. 